\title{
A Solid Variant of Aneurysmal Bone Cyst of Maxilla
}

\author{
V. K. Kataria, Assistant Prof., S. K. Bhansali, Head of the Deptt., \\ B. S. Mehta, Resident in ENT Deptt., \\ B.J. Medical College Ahmedabad
}

\begin{abstract}
A solid variant of Aneurysmal Bone cyst is very rare tumour of maxilla. Histopathologically it is very much similar to giant cell granuloma but the radiographic features can influence the pathologic interpretation.

A solid variant of anenurysmal bone cyst has been reported in facial bones and it can involve several adjacent bone synchronously (3). Both giant cell granuloma and aneurysmal bone cyst have a propensity for recurrence variably in the $15 \%-26 \%$ range (5).
\end{abstract}

\section{Case Report}

A 25 year old female presented in the E.N.T. O.P.D. with a swelling over left-side of face and upper alveolar region, with mild pain off and on since one year. (Fig -1)

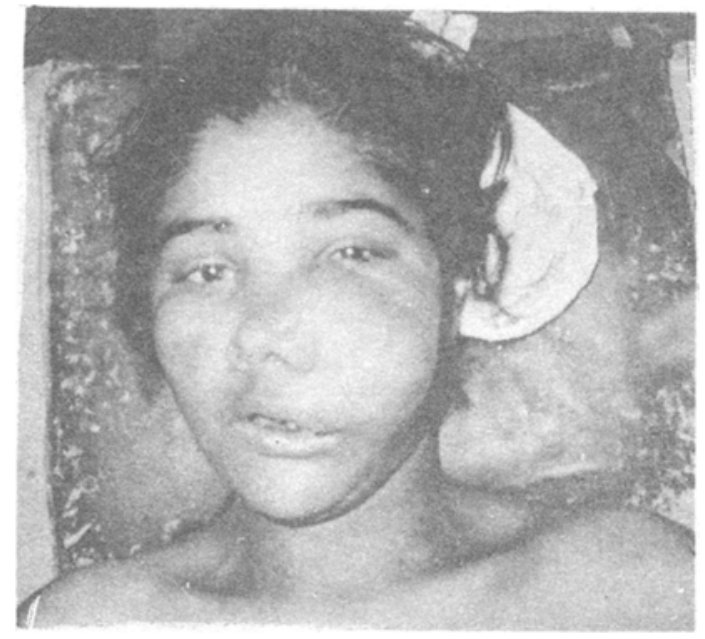

Fig. I Photograph showing swelling over Left-side of the face

No history of epistaxis, trauma or surgery. History of 5 month amenorrhoea was there. On clinical examination there was a big swelling in the left maxillary region approximately $12 \times 10 \mathrm{~cm}$ in size. It was extending from inner canthus and bridge of nose to upper lip to anterior border of masseter muscle. Tumour was tense and mildly tender. Hard palate on left side was also involved and bulged in oral cavity. Left upper teeth were loose except molars. On anterior rhinoscopy the left Lateral wall of nasal cavity was pushed medially. Investigations showed mild anaemia. Liver Function Tests and Renal Function Tests were normal.

X-ray P.N.S. showed haziness on left side.

C.T. Scan of P.N.S. was reported as benign expansile tumour of left maxilla possibly an aneurysmal bone cyst of Ostesclantoma. (Fig - 2 \& Fig - 3)

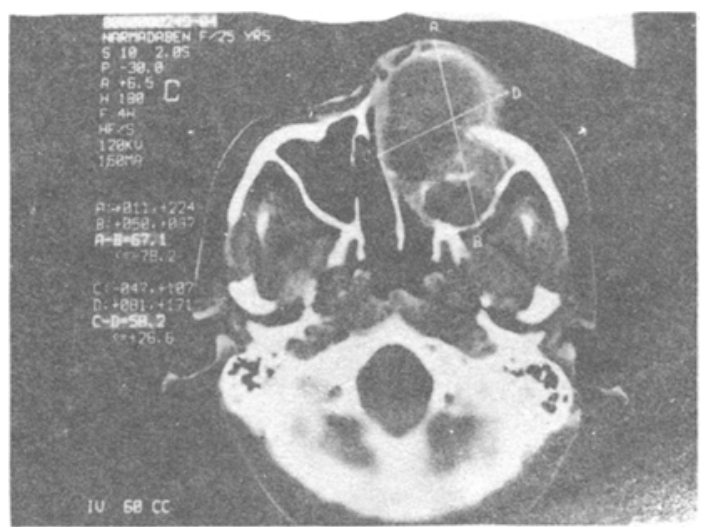

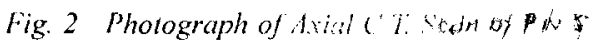




\section{Management}

Patient was pregnant and anaemic So pre-operative 3 Blood transfusion was given and started inj. Tidilan 24 hours before and continued for 15 days to preserve pregnancy. Pre-operative dental opinion was taken for temporary and permanent prosthesis.

Patient was taken under General Anaesthesia. left external carotid artery was ligated to minimise blood loss.

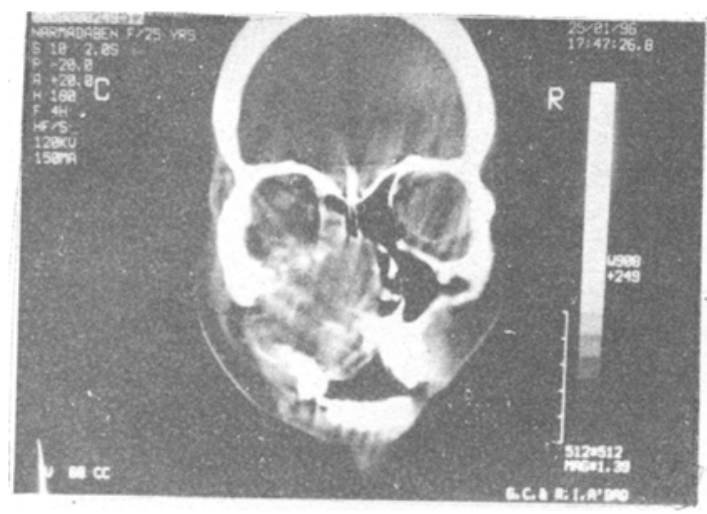

Fig. 3. Photograph of Coronal C.T. Scan of P.N.S.

Left total maxillectomy was done by Weber furguson approach. Tumour was removed in toto with tumour free margins. (Fig-4)

Temporary dental prosthesis was kept and packing done. The wound was closed in layers. Post operative period was uneventful.

Pack was removed on 4th day and stiches were removed on 7 th day. The scar was well healed.

Patient. was discharged after completing a course of inj. Isoxsuprine (Tidilan' uterine muscle relaxant) for 15 days as per Obstract \& Gynecologist's opinion. Also refered to Dental surgeon for permanent prosthesis. On macroscopic exam. there were cystic areas with bony septa. Histopathological report was a solid variant of aneurysmal bone cyst of maxilla.

\section{Discussion}

A solid variant of aneurysmal bone cyst is a solitary expansile lesion of bone containing irregular blood filled spaces. Usually seen in patients between age of 10 to 30 years (2). It occurs mainly in the vertebra and flat bones but can also arise in the shaft of long bones (4).

A solid variant of aneurysmal bone cyst has been reported in the facial bones and it can involve several adjacent bones synchronously (3).

Giant cell granuloma and aneurysmal bone cyst having histologic overlap.

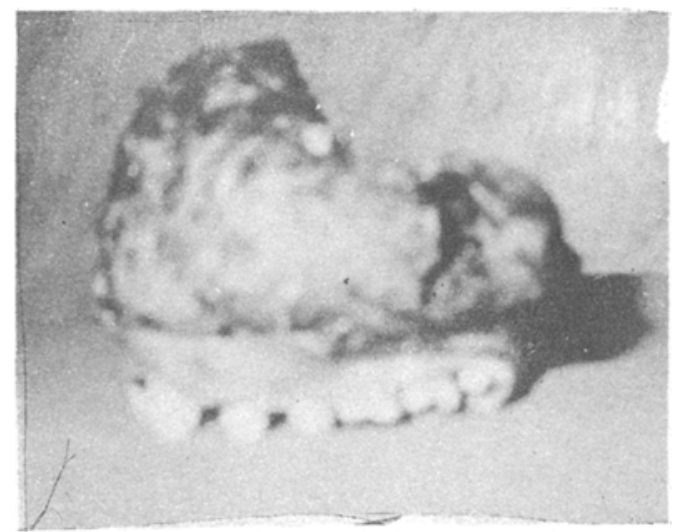

Fig. 4 Photograph of excised mass with maxilla.

The age range and slight predilection for females is similar for both lesions. Histologically giant cell granuloma consists of spindle, avoid or round histiocyte like cells set in well vascularized fibrous tissue. The cells are mononuclear, binuclear, trinuclear and eventuate as giant cells.

Osteoid is formed within the center as well as the periphery of the lesion, with extravasation of blood is focally prominent. The same histologic description also applies to the broad septa and solid areas that occurs in aneurysmal bone cyst, including the propensity for giant cells to line vascular spaces.

That is why the radiographic features can influence the pathological interpretation (4).

In retrospect some lesions called giant cell granuloma are better classified as solid aneurysmal bone cyst. (1) Both giant cell granuloma and aneurysmal bone cyst have a propensity for recurrence. That is variably reported in the 15\%-26\% range. As with aneurysmal bone cyst of long bone there may be underlying lesion such as fibrous dysplasia also with aneurysmal bone cyst of facial bones (5). 


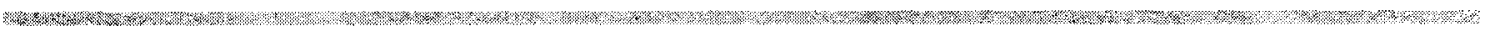
Reference

Fto

1) Fenchner R. F. Fitz-Hugu G.S., Pope T.L. Jr. (1984) : Extraordinary growth of giant cell reparative gramuloma during pregnancy. Arch. Oto. 110;116-119.

2) Patrick C. H; Watt, Roy A. J. Spence (1986) : Patho. For surgeons. 565-566.

3) Sanarkin N.G., Mott M G Roylance S. - (1983) : An unusal intraosseous lesion with fiberoblastic, Osteoclastic, Ostesblastic aneurysmal \& fibromyxoid elements of solid variant of aneurysmal bone cyst. Cancer $3 ; 51: 2278$ 2280.

4) Stephen S. Sternberg Diagnostic surgical pathology volume - I, IInd edition - 861.

5) Struthers P.J. Shear M. (1984) : an aneurysmal bone cyst of the jaws (l) Clinicopatho Featurs. Int. Jr. oral surj. $13: 85-91$.

\section{Conference News}

We feel great pleasure in informing that Department of E.N.T. Himalayan Institute of Medical Sciences, Dehradun organised a Sympo-Seminar on Noise Pollution on 17.5.98, which was attended by 68 delegates which included E.N.T. Surgeons, General Practitioners, Audiologists, Industrialists, Hearing Aid Manufacturers, Medical Students and General public. It was a one day affair in which-Present status, Etiology, Effects, Detection, Audiological evaluation, presentation and prevention of Noise Pollution was discussed in detail. Prior to sympo-seminar a Slogan writing competition was organised in Hindi \& English for general public and three awards in each category were given to general public. One hour interaction of the expert panel i. e. E.N.T. Surgeon, Audiologist, Industrialist \& Hearing aid manufacturer with general public was there to answer queries of public.

Organising secretary of the sympo-seminar was Dr. Saurabh Varshney Assistant Professor (E.N.T.), Himalayan Institute of Medical Sciences, Dehradun (U.P.). Dr. R. C. Deka, Prof. \& Head, Department of E.N.T. \& Head Neck Surgery, A. I.I.M.S., New Delhi was the Guest Speaker. It was the first of its kind programme in this area. Sponsorship was from Ministry of Environment \& Various pharmaceutical companies.

Last year also Department of E.N.T., Himalayan Institute of Medical Sciences, Dehradun organised two days workshop on F.E.S.S. on 30.11.97. \& 1.12.98, which was attended by 32 E.N.T. Surgeons and live surgery demonstration with video display and two way talking system was there. Dr. Devendra Rai, Sr. Consultant Ganga Ram Hospital, New Delhi was the Guest Surgeon and about 8 cases were operated. 